\title{
The Cultural Limits of Challenging Hegemonic Masculinity: Critical Analysis of Online Responses to Axe Turkey Advertisements
}

\author{
Alparslan Nas
}

\begin{abstract}
Hegemonic masculinity has been a challenging concept in cultural studies since the 1990s. Throughout the past three decades, the concept has been carefully applied to the critical analysis of gender in several academic fields, including media studies. Many studies have defined hegemonic masculinity as a locally significant and dynamic concept that is open to various interpretations across different cultural representations and experiences. This article offers a culturally specific analysis of the representations and receptions of hegemonic masculinity in Turkish advertising discourse. For this purpose, this article analyzes Axe Turkey's two advertisements that were released for International Women's Day in 2018. The advertisements challenged hegemonic masculinity in Turkish culture by carrying critical narratives. The advertising discourse met with a variety of audience responses through online comments. Content analysis of the online responses revealed a dominant trend in the audiences towards restoring the hegemonic masculine order by applying several discursive strategies against the advertising narrative.
\end{abstract}

KEYWORDS advertising, content analysis, discourse, hegemonic masculinity, Turkey

\section{Introduction: "Apologizing" in the Era of Hegemonic Masculinity}

Hegemonic masculinity has been one of the most debated concepts within cultural studies in the past three decades. The notion was initially formulated by Raewyn Connell $(1987,1995)$, who offered a critical model to comprehend the reproduction of masculinities in a hegemonic order. Referring to Antonio Gramsci's notion of "cultural hegemony", as a class strategy to maintain the consent of the dominated, Connell's (1987: 183) analysis pointed out the different practices by which men exercise their dominance vis-avis women and other men: "Hegemonic masculinity is always constructed in relation to various subordinated masculinities as well as in relation to women". In this regard, studies of hegemonic masculinity have undertaken a critical elaboration of masculine practices and discourses that reproduce or legitimize masculinist superiority in an active process of generating the consent of the subordinated (Messerschmidt 2019: 86). The hegemonic masculine order positions some men in an advantageous position to exercise power in the "patriarchal dividend" (Buschmeyer and Lengersdorf 2016: 196). Finally, Connell

Sociálni studia / Social Studies 2/2021. S. 67-86. ISSN 1214-813X. https://doi.org/10.5817/SOC2021-2-67 
(1995: 109-114) points out the fragmentariness of masculine identity by formulating non-hegemonic types of masculinity: complicit, subordinate, marginalized, and protest. The fragmented experience of masculinities attests that masculinity is a dynamic field distinguished by a constant generating of consent and negotiation of power (Connell and Messerschmidt 2005: 831). Ultimately, Connell's conceptualization of hegemonic masculinity is crucial to expose patriarchal culture as a complex gender order which inhabits power relations and resistance.

The analysis of hegemonic masculinity has set the agenda for critical research on the representation of masculinities in the media. As a crucial space for negotiating gendered meanings, media representations of masculinities are spread across various mediums, including film, television, advertising, journalism, and digital media. Among these mediums, advertising historically instated a domain of power relations where commercial culture and gender intersected in the reproduction of the hegemonic masculine order. Recent transformations in advertising discourse demonstrate the emergence of unconventional narratives on gender that point out the problems of patriarchal culture. In this era, in addition to the narratives that focus on women's issues, several brands that target male consumers have offered challenging discourses on masculinities. In this regard, this article analyzes two advertisements by Axe in Turkey, "We apologize if we hurt you" and "We are not remaining silent", released for International Women's Day in 2018. The advertisements criticize hegemonic masculinity in Turkish culture by holding it responsible for women's subordination. The main narrative of the advertisements rests on "apology", as several men beg forgiveness from their partners for their wrong deeds. The advertisements openly situate men as perpetrators and point out the hegemonic culture of masculinity in Turkey. This article engages in the analysis of online responses published on the advertisements' official YouTube pages by conducting a content analysis. Although there have been many advertising campaigns supporting women's empowerment in Turkey, Axe's campaign is unique in terms of focusing on men's guilt and calling for self-criticism and apology, which tend to shatter the cultural foundations of hegemonic masculinity. The investigation of online comments is essential to discern the impact and the limits of the critique against hegemonic masculinity proposed by the advertisements in Turkey's patriarchal cultural dynamics.

\section{Hegemonic Masculinity in Post-Feminist Media Culture}

Historically, advertising has been criticized for constructing gender discourses that tend to reproduce patriarchy, hegemonic masculinity, and sexism (Goffman 1979; Jhally 2006; Williamson 1978). Not simply a marketing tool, advertising functions as "an integral part of modern culture" by managing to produce symbols, ideas, and discourses on objects (Leiss et al. 1990: 5). Critical studies on the social impact of advertising pointed out that advertisements are responsible for creating "false needs", manipulating consumers and reproducing the mechanisms of social control and ideology (Leiss et al. 1990: 22-30). Raymond Williams (2000) characterizes advertising as a "magic system", which facilitates a symbolic order for the exchange of goods based on subjective meanings rather than objective structures. Debating the power of advertising to represent reality, Jhally (1990: 136) argues 
that advertising images are "neither false nor true reflections of social reality", since they are themselves part of social reality. Gender plays an important role in advertising imagery since, as Jhally (1990: 135-136) remarks, "gender is one of our deepest and most important traits as human beings", and can be easily communicated to the public via conventional codes.

Historically, gender representations in advertisements during the 1980s and earlier were primarily based on the objectification of women as passive victims of patriarchy (Gill 2007: 151). One outcome of the heightened visibility of the feminist critique of advertising was a transformation in the 1990s and the 2000s in advertising language, which shifted its imagery towards women with active agency, mainly through a discourse on beauty and sexuality (Goldman 1992: 3; Lazar 2014: 206). The new advertising language pointed out a different problematic in terms of the sexual subjectification of women by commercial culture, which disguised itself under the discourse of equality and empowerment (Gill 2007: 152-153). Subsequently, advertising narratives shifted in focus towards feminist arguments, as many brands inaugurated advertising campaigns challenging patriarchal culture and promoting gender equality (Murray 2013). Angela McRobbie (2004) and Rosalind Gill (2008) pointed out the problematic discourse constructed by the new advertising language, which tended to commercialize women's issues and demands by using the discourse of female empowerment. The new advertising language also idealized the representation of women by disregarding women's problems in terms of age, ethnicity, religion, disability, and sexual orientation. Critical interventions by feminist scholars facilitated discussions of "post-feminism", pointing to a unique sensibility in popular culture about gender equality, and incorporating opportunities, impossibilities, and limitations for modifying gender hierarchies.

In their article "Marketing Manhood in a 'Post-feminist' Age", Barber and Bridges (2017) offer a critical analysis of how hegemonic masculinity continues to be a vital discourse in advertisements in the post-feminist era, which is marked by growing widespread criticism of gender inequality in advertising. According to the authors, while contemporary advertising increasingly applies feminist discourses that incorporate women's active agency in commercial interests, challenging hegemonic masculinities through advertising is a relatively new process. Since the 1970s, feminist scholarship and activism have prioritized the representations of women as subordinated subjects in commercial culture. The challenges to sexism in advertising prompted the emergence of new advertising language in the following decades that incorporated female empowerment in marketing messages. However, the problematizing of masculinities has not impacted marketing narratives as urgently and sharply as the feminist critique on women's subordination. Contemporary debates on masculinities demonstrate a growing tendency to challenge masculinities in culture and media representations. As an outcome of this process, several global brands, including Axe and Gillette, launched campaigns in the second half of the 2010s to challenge hegemonic masculinity and promote alternative, hybrid, or subordinated masculinities (McCluskey 2019; Nudd 2017). The transformation in the advertising discourse regarding masculinities by Axe and Gillette shows that these brands refuse to reproduce previously established stereotypes of manhood and instead are introducing a new language to their consumers. The appearance of a critical advertising discourse signifies the expanding trend 
in promulgating, problematizing, and marketing manhood in diverse cultural contexts. Ultimately, not only women but also men have become the subjects of a distinct commercial discourse in the age of post-feminism.

\section{Masculinities in Advertising Discourse}

In their article "Hegemonic Masculinity: Rethinking the Concept", Connell and Messerschmidt (2005: 849) develop the notion of hegemonic masculinity by pointing out the diverse ways in which masculinities are reproduced in local, regional and global contexts. On the local level, masculinities are constructed in the daily interactions of individuals in their ordinary lives, whereas the regional level involves the making of masculinities on the cultural and nation-state levels. As a third category, the global level is significant to address the constructions of masculinities in the transnational sphere, particularly in businesses and the media. Connell and Messerschmidt argue that there is an interplay between the three levels since the practices of hegemonic masculinity can be detected at the local level through individuals' interactions, which can have regional significance. On the other hand, global institutions can have an impact on the shaping of local and regional gender orders (Connell and Messerschmidt 2005: 849). In between the local and global levels, the authors underscore the significance of the regional level since it consists of the significant cultural sphere which manages to shape hegemonic masculinity by mediating between the individual practices and global trends (Connell and Messerschmidt 2005: 850).

The Turkish experience of the critique by social media users of hegemonic masculinity through Axe's regional campaign beautifully illustrates Connell and Messerschmidt's arguments on the interplay between local and global levels in the negotiation of hegemonic masculinity. Axe's campaign prominently criticizes the cultural understanding of hegemonic masculinity on the local and regional levels by introducing the brand's global point of view. The audiences counter the critical insights offered by the brand from the global perspective by confirming or rejecting the brand's criticism. The audience's participation in this process attests to the negotiations between the local and the global discourses of masculinities. In this regard, advertisements forge a discursive battle between the regionally shaped gender order and a global emancipatory discourse that tends to deconstruct the local manifestations of hegemonic masculinity. Beasley (2008: 96) argues that hegemonic masculinity can be critically evaluated as a "political ideal" on the level of discourse, in response to Connell's insistence that hegemonic masculinity is a practice reflected in the material domain of social experience. In this respect, advertisements constitute a major discursive technology that is capable of participating in the power struggles through regionally and globally located narratives.

Many studies have pointed out the interplay between advertising narratives and masculinities, and analyze the broader cultural and global mechanisms of discursive formation of hegemonic masculinity. The current scholarship on the issue can be divided into three main categories in terms of their distinct elaboration of advertising discourses. The first category of scholarly inquiry focuses on how advertisements reproduce hegemonic masculinity (Gee and Jackson 2012; Jackson 1994; Luyt 2012; Patterson and Elliot 2002; Rogers 2008; 
Schroeder and Zwick 2004; Towns et al. 2012). Similarly to Connell's formulation of hegemonic masculinity as a cultural practice of consent among men and women, these studies focus on the authoritative role of advertising in normalizing and legitimizing masculinist discourses. The second category of investigation underscores the potential of advertisements to challenge hegemonic masculinity in different historical periods and cultural contexts (Feasey 2009; Harrison 2008; Jester 2019). This category depicts how advertisements criticize hegemonic masculinity by rendering visibilities of alternative, subordinate, or marginalized masculinities. Despite pointing to the critical potential of advertising in this manner, these authors acknowledge the commercial prospects of advertisements and how the capitalist gender regime brands the opposition to hegemonic masculinity.

The third category of scholarly interest draws attention to the discursive strategies employed in the advertisements which challenge and, at the same time, paradoxically reproduce hegemonic masculinity. Studies in this category analyze the advertisements, media items, and daily life practices by pointing to their ambiguities and limitations to offer a liberating discourse that is capable of challenging hegemonic masculinity by referring to the process of "masculinizing" (Greenebaum and Dexter 2018; Hardin et al. 2009; Klasson and Ulver 2015; Leader 2019; Scheibling and Lafrance 2019). Through this practice of masculinizing, advertisements portray men who are actively engaged in activities that are not culturally defined as masculine, yet they concurrently reproduce a different version of an ideal manhood through their alternative or marginalized engagements. The masculinizing perspective denotes the discursive constructions of masculinity as a dynamic concept that is delineated by the ongoing strife over gendered power relations. The dynamism of the notion of hegemonic masculinity as described by several authors (King 2009; Prody 2015; Johansson and Ottemo 2015) compels the analysis of how advertising discourses are composed, acquired, and countered by audiences, which would shed light on the complex mechanisms of power.

This research will concentrate on how the process of masculinizing occurs in Axe Turkey's advertising campaign and focuses on audience comments to estimate how masculinizing takes place in the digital culture. In the Turkish context, hegemonic masculinity has been discussed by many authors from sociological, anthropological, and political perspectives (Atuk 2019; Boratav et al. 2014; Ekşi 2019; Keskin 2018; Ozbay and Soybakis 2020). However, media analysis, particularly analysis of how advertisements reproduce or challenge masculinities, has been neglected. Axe's advertisements, entitled "We apologize if we hurt you" and "We are not remaining silent", represent the experiences of manhood that perpetrate violence and discrimination against women. Moreover, there are depictions of marginalized and subordinate masculine and feminine identities that tend to challenge the traditional gender order in Turkish culture. Axe's challenging of hegemonic masculinity in Turkey started in May 2017, when the brand released its first advertisement, "Men cry too", as a music video performed by Turkish rock star Can Bonomo. The song is a critique of the cultural understanding of crying as a sign of vulnerability that challenges the toughness represented by hegemonic masculinity. As I analyzed elsewhere (Nas 2017), the majority of the online responses to the advertisement consist of the approval of the brand's main argument, that is, men can also cry and that this should not be regarded 
as an inferior behaviour. However, strikingly the comments also tend to reproduce hegemonic masculinity by addressing men's crying with statements such as "men do cry, and they cry best", "if a man cries, no one can stop him", "men cry and the world will tremble". Eventually, the online comments discursively performed a process of masculinizing the advertisements' narrative. The audience response was crucial to analyze the dynamism of hegemonic masculinity, and the power struggles to challenge or legitimize this notion. In the following sections, this article will engage in the critical analysis of Axe's latest advertisements to examine the discursive contest between the brand and its audiences.

\section{Note on Methodology}

In assessing how the audience comments relate to more comprehensive social conceptions of hegemonic masculinity, this analysis will blend quantitative and qualitative approaches through content analysis. In this regard, this paper will analyze the user comments about two advertisements, which were published by Axe on the company's official YouTube page in 2018, called "We apologize if we hurt you" and "We are not remaining silent". According to Lune and Berg (2017: 192), content analysis "examines a discourse by looking at patterns of the language used in this communications exchange, as well as the social and cultural contexts in which these communications occur". In this respect, the analysis will first sketch out the major recurring themes and motives in audience responses by a quantitative analysis to collect data. The data gathered then will be coded and interpreted qualitatively to critically discuss how the critique of hegemonic masculinity is reinforced or opposed by the words of the audiences. The coding process will follow "axial coding", whereby the main coding frames are first determined, followed by inserting specific themes under the coding frames (Lune and Berg 2017: 193). The frames and sub-themes will be discussed comparatively by referring to the advertisements. Eventually, the quantitative data accompanied by the qualitative analysis will allow us to estimate the notable themes and discourses that emerge from the online responses.

Besides, the limitations of the research should also be addressed. Since the analysis is limited to the comments published under the YouTube videos, real identities of users cannot be accessed. Particularly in the comments that affirm the brand's intended message, there is a possibility that some of them could be published by users paid by the brand to support their advertisements. Yet, since these affirming statements did not dominate the comments, it became possible to observe a heterogeneous sample consisting of variety of other responses and arrive at certain conclusions regarding how the advertisements were decoded by the viewers.

\section{"We Apologize If We Hurt You": Masculinizing Through Celebrity Culture}

Axe's initial advertisement for International Women's Day was published online on YouTube on 6 March 2018. ${ }^{1}$ The video received 5.7 million views as of March 2020. The description

\footnotetext{
$1 \quad$ Retrieved from https://www.youtube.com/watch?v=WJqqr5GQkCM
} 
of the video introduces the following sentences and the hashtag: "Insistent to those who say 'men do not apologize', we continue to break the taboos with Can Bonomo and beg forgiveness. \#KırdıysakÖzürDileriz (\#WeApologizeIfWeHurtYou)". The descriptive sentence refers to the previous campaign, which was initiated in 2017 with the song "Men Cry Too" by Can Bonomo and represented another occasion to challenge the cultural stereotypes of manhood established by hegemonic masculinity. The video consists of another popular Turkish song, "Forgive Me", covered by Can Bonomo in his unique rock style, and lasts 2:56 minutes, with the lyrics translated as follows:

Forgive me / it is too early to lose / too late to love / forgive me / there has to be a way / as a result of broken things / in the wake of solitude / forgive me / when I loved you in this city / it rained / when I loved you in this city / separation was as heavy as lead / forgive me / poems did not tell your eyes / songs did not tell your hair / forgive me / there has to be a way ...

The video clip's visual narrative can be divided into two segments. First, the narration depicts several couples experiencing conflict and disappointment in various settings. In the second part, the men who are blameworthy approach their partners and apologize, and finally they reconcile the relationships. There is an equal representation of men and women in the narrative, as both genders are noticeable in the conflicting and reconciling relationships. The advertisement goes beyond the mainstream cultural heteronormative matrix by including a scene depicting one man apologizing to his male partner, and in another scene where a man is apologizing to a drag queen in his/her dressing room. The video was released for International Women's Day, but the narrative is not constrained by heterosexual relationship dynamics among men and women. In this regard, the narrative disputes the culturally established understanding of manhood as a heterosexual construct, and men as exempt from the act of apologizing despite misbehaviour.

This research has carried out with comments published under the video between 6 March 2018 (video's publication date) and 3 March 2020 when the research was conducted. From a total 282 audience comments, 199 of them were included in the first analysis of coding frames. During the retrieval of the initial data, a group of comments were identified and excluded from the sample since they were including writings on other irrelevant subjects, personal dialogues with or replies to other commentators, spam content that promoted other channels or websites, swear words not related to the video discussion, and ambiguous statements or emojis that were not properly intelligible. Since the main query of the research deals with how the audience reacts to the criticism of hegemonic masculinity in advertisements, the main coding frames were set as "confirming responses" and "rejecting responses" (Figure 1). The first coding procedure showed that 180 of 199 comments $(90.5 \%)$ confirm the advertisement's critical narrative in varying ways. Only 19 responses $(9.5 \%)$ negatively react to the advertisement. By further coding, sub-themes were ascertained under the confirming responses to analyze the data more efficiently. In the second coding, four main themes were established: "Critical appreciation" (n: $16=8.9 \%$ ), "Brand liking" (n: $8=4.4 \%$ ), "Song liking" (n: $68=37.8 \%$ ), and "Celebrity liking" (n: $88=48.9 \%$ ). The first theme of critical appreciation entails audience comments directly occupied with critiquing the hegemonic masculinity that the advertising narrative offers. The second theme 
of brand liking consists of comments which uphold Axe's positive image as a brand in dealing with cultural issues. The third theme of song liking comprises responses to the song, expressing appreciation as a good piece of music. Finally, the fourth and most significant theme includes audience reflections confirming the advertisement through the liking of Can Bonomo's image as a celebrity figure.

Figure 1: Analysis of online responses for "We Apologize If We Hurt You"

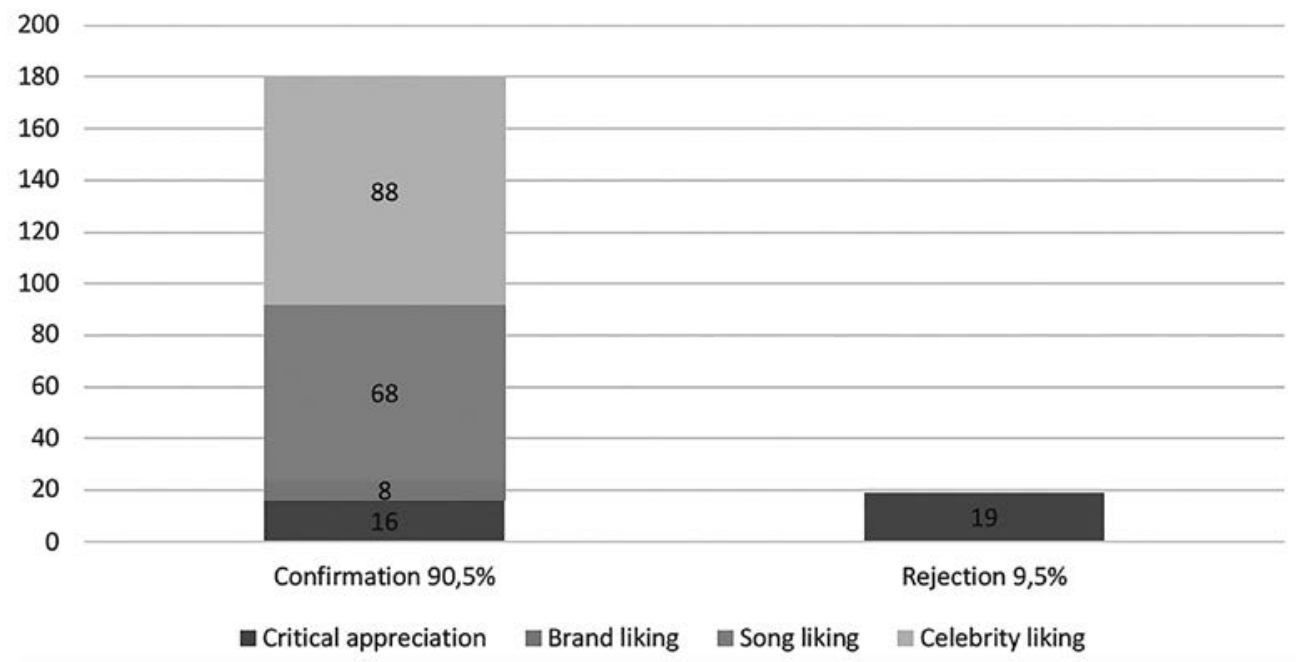

In terms of the negative responses ( $\mathrm{n}$ : 19, 9.5\%), it is significant to note that none of the audience comments focus on the critical content of the advertisement as the basis of their objections. Instead, these responses mainly focus on the quality of the song and comparisons between other versions of this song and Can Bonomo's performance. Other than these commentaries, the adverse reactions do not negate the criticism of hegemonic masculinity or legitimize the hegemonic-masculine order. Therefore, it is not possible to estimate how audiences reacting negatively to the advertisement actually judge the ideological content of the video.

On the other hand, most positive responses can be categorized into four main themes, with the majority focusing on the liking of the brand, song, and the celebrity singer. Only a limited number of comments directly engage in analyzing the meaning of the advertisement (n: $16=8.9 \%$ ), which is categorized as critical appreciation of the advertisement. In this regard, some comments state the following:

Men can cry too, men can get upset too, men apologize, men can get powerless. But none of these indicate desperateness. They are signs of being human. Do not judge people for their human emotions!

As in many things, there is no gender in apology. Continue to break the taboos. 
Ceren Ozdemir, Emine Bulut, Dilan Tutucu, I cannot forgive Turkey, I cannot forgive...

Forgive us, we could not save you, we could not be your voice, we left everything to time...

The commentaries almost rephrase the main argument of the advertisement by focusing on the deconstructions of hegemonic masculinity. These comments critically assess the making of hegemonic masculinity in Turkish culture and widely support the advertisement's main point of critique. While the first two comments underscore the advertisement's message with an imprecise recognition, the last two quotes focus on culturally specific issues such as femicides in recent years. As emphasized in the quote, Ceren Ozdemir, Emine Bulut, and Dilan Tutucu were the victims of femicides, which captivated public attention in Turkey. Concerning contemporary issues of violence targeting women, the commentaries discuss the possibility of forgiving these atrocities by being incited by the critical tone of the advertisement.

The rest of the themes under the positive response category are different elaborations of liking, directed towards the brand, song, and the celebrity singer. Among these themes, a minority of comments ( $\mathrm{n}: 8,4.4 \%$ ) express that they like the brand acknowledging gender equality with statements such as, "I will certainly continue using Axe after this apology", "That is why Axe is my choice!", and "You are a wonderful brand". It should also be acknowledged that these comments could be published by users financially supported by the brand to create a positive impression of the advertisement. The second liking category (n: $68,37.8 \%$ ) consists of comments that focus on the niceness of the song, by citing its lyrics and sharing brief comments that include emojis as a sign of appreciation for the music: "Perfect song", "This song deserved a wider audience", "It is too early to lose, too late to love...", "There is a quality here", "There is quality in the sound, it doesn't tire me", "each time I listen to it, the same quality", "wooow (smiley emoji)". These comments are concise indicators of how audiences are attracted to the song, mainly by getting emotional due to the lyrics and attributing a certain quality to the music. The third and most common theme among the positive responses consists of comments that glorify Can Bonomo - almost half the responses are in this coding frame (n: 88, 48.9\%). Overwhelmed by the celebrity figure, many listeners comment on the positive qualities of Can Bonomo and the prominence of his presence in the advertisement as the primary source of their attraction, such as the following:

The difference of Can...

Can Bonomo, a person who makes songs more beautiful and meaningful.

The man has peace and love in his voice.

If a man is a real man, he should apologize, you are perfect Can.

Can and perfection, side by side.

You are a legendary man.

The best rock singer in recent years. 
You are a wonderful detail.

Can Bonomo, a man like a man, who sounds a man's emotions in the best way.

Can Bonomo, you are a revolution.

I am in love with you.

The comments strongly appreciate Can Bonomo as an exhilarating rock singer who has performed well in his career, including this recent performance. Nevertheless, what is more striking in the comments is how the audience responses reproduce an alternative version of hegemonic masculinity based on Can Bonomo's charismatic persona. Many comments refer to Can Bonomo as "the man" with a marvellous talent and robust effect. Bonomo's "manhood" is repeatedly emphasized to indicate his inspiring performance and applied to the audience's comments about enjoyment of the song. Although the comments initially seem to approve the song and its main critical argument by making positive remarks, the devotion to the male celebrity figure re-establishes the boundaries of hegemonic masculinity. As an outcome, the positive responses coding frame includes 16 comments $(8.9 \%)$ which directly engage with the narrative of the advertisement. While the remainder of the comments are also positive, it is complicated to estimate how these comments engage in the critical understanding of hegemonic masculinity. The audience's endorsement of the video does not necessarily mean that they agree with the social criticism advanced by the brand. Contrarily, many comments tend to restore and legitimize hegemonic masculinity through Can Bonomo's domineering personality, which paradoxically also form positive reactions to the advertisement.

\section{"We Are Not Remaining Silent": Rejection of Apologetic Masculinities}

Axe's second advertisement for International Women's Day appeared one day after the first advertisement, on 7 March 2018, on YouTube. ${ }^{2}$ The video received over two million views as of March 2020. The title and the hashtag of the video were "We are not remaining silent", with a brief explanation stating that "Staying silent against what is done to women does not fit into manhood". In an attempt to initiate men's critical perspective towards women's subordination, the brief explanation paradoxically points to an essential definition of "manhood", as will be addressed in several of the objections by online users. Similar to the first advertisement, the narrative proceeds with two main parts. The first part highlights several men who are about to offend women with whom they interact, such as a man at the office in a mobbing scene, a man following a woman in the street, and a man stalking a drag queen from his vehicle. In the second part of the narrative, these men stop their acts, come face to face with the women with whom they interact, and apologize. At the beginning of the apology scenes, "Staying silent against what is done to women does not fit into

2 Retrieved from https://www.youtube.com/watch?v=5aI83W_uazU\&t=1s 
manhood" appears on the screen. Finally, the advertisement ends with the main slogan and the hashtag, "We are not remaining silent".

Similar to the first advertisement, the narrative focuses on the act of apologizing as a means to deconstruct the cultural stereotypes that tend to reproduce hegemonic masculinity in discourse. The video proceeds by portraying how men are responsible for women's subordination by various violent acts. The narrative tends to go beyond heterosexual normativity by including an encounter with a drag queen, similarly to the first advertisement. Besides the related motives, there are three significant differences between the two advertisements. First, the second advertisement is not a song, and maintains a different narrative strategy to encourage the audience to focus on the problem rather than the song as a form of entertainment. Secondly, the narrative addresses women explicitly with its slogan and includes a clear reference to male-female power hierarchies, a different motive from the first advertisement. Finally, the act of apology is more visible and concrete in the second advertisement as men utter the word "I apologize". Rather than Can Bonomo announcing the apology in the first advertisement, the second advertisement is more direct in its depiction of apology as a criticism of hegemonic masculinity. As will be discussed in the following part, these differences and similarities are reflected in how the audiences receive the second advertisement's argument in alternating ways, which digresses from the first advertisement.

Similar to the methodology applied to the first video, comments published between 7 March 2018 and 3 March 2020 were gathered and sampled according to their relevance on the subject. Among 268 comments, 178 comments were included in the sample and irrelevant content were excluded. Comparable to the first advertisement's coding frames, online comments are divided into two categories of confirmation and rejection (Figure 2). A total of $37.6 \%$ ( $n$ : 67 ) comments positively evaluate the advertisement's challenging of hegemonic masculinity by approving it in various ways. Contrarily, $62.4 \%$ (n: 111) responses oppose the critical narrative offered by the advertisement. In further coding to understand the reasons for opposition, three main themes are established to illustrate how the online comments tend to reject the advertisement's narrative in distinct ways. According to this thematization, "Questioning the brand's intention" constitute the $34.2 \%$ (n: 38 ) of the negative responses. These comments include reflections sceptical of the brand's intention to deliver a counter-narrative on gender. Second, $44.2 \%$ (n: 49) of the negative comments tend to reproduce hegemonic masculinity, which ultimately opposes the critical narrative posed by the advertisement. As a third theme, 21.6\% (n: 24) of the negative comments engage in a feminist critique of the inappropriateness of apology from a judgmental viewpoint. These explanations commonly point out the limits of the campaign by critically negotiating its discourse, notably its slogan that upholds "manhood" and places the possibility of apology on this very problematic spot. 
Figure 2: Analysis of online responses for "We Are Not Remaining Silent"

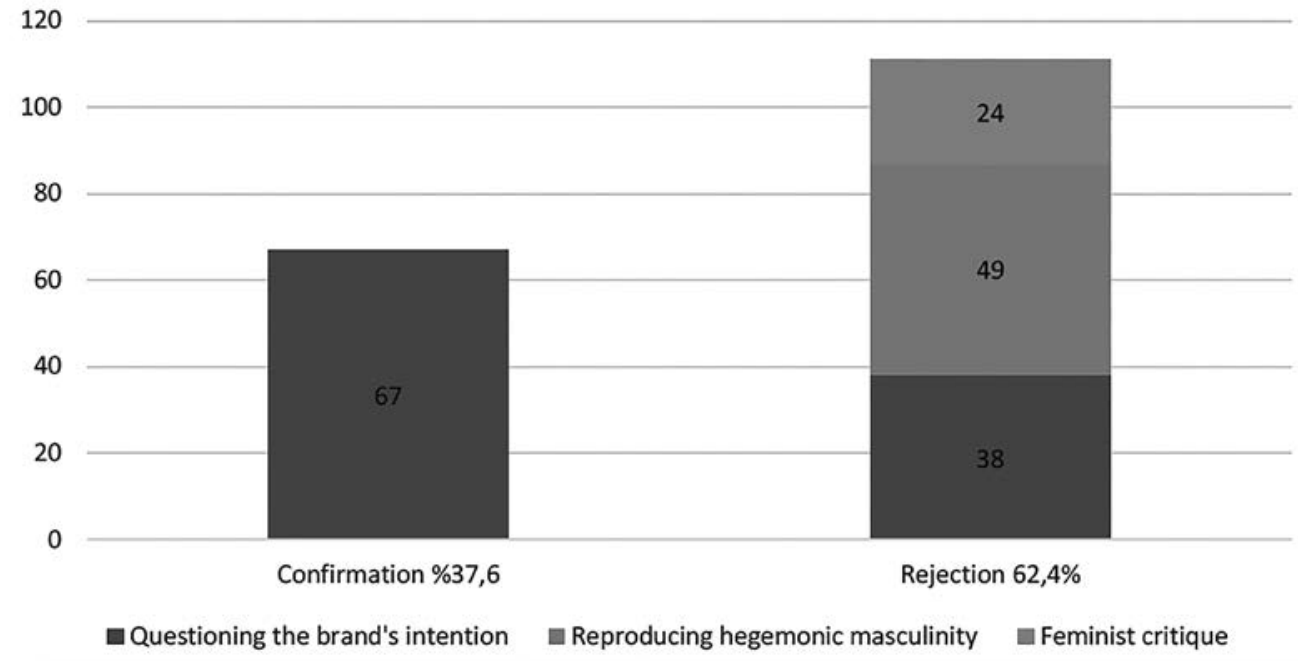

The confirmation category that includes affirmative responses to the video is highly monolithic in terms of the acceptance of the oppositional narrative conveyed by the advertisement $(37.6 \%$, n: 67). For this reason, this category has not been divided into sub-themes for further content analysis. Nonetheless, while some of the comments approve the video, some others respond to the negative comments published by other users. Positive responses highlight the social context to which the advertisement refers and approve the act of apology made by men in the video in diverging ways. Some of the remarks are issued as follows:

No to femicide!

I was startled when I have seen the beginning of the video...

Normally we would not expect a commercial company to produce such a video but great for them.

Violence cannot be normalized and legitimized, the world will become a better place to live once everybody begin to respect each other.

We are sorry! I wonder how many people understood this phrase correctly?

Very meaningful, impressive, thank you.

We are not remaining silent!

Happy International Women's Day!

Congratulations, this is what a man is expected to do.

A man who beats a woman is a pathetic being. 
As stated above, many comments approve the advertisement's opposition to hegemonic masculinity by pointing out issues of violence, cultural constructions of manhood, appreciation for the brand's position, and the enacting of the brand's slogan, "we are not remaining silent". Besides these positive responses, some comments react to the negative comments published in the thread. These comments explain the advertisement's main intention and defend criticism of hegemonic masculinity in varying ways, as opposed to the retrogressive comments on the matter. Some of these responses are stated as follows:

I still cannot believe that you are saying "where is the men's day, nobody thinks of us." As a man, I apologize to all women.

3000 dislikes? Come on! This is not even Middle East, but Africa!

All rapists, violence promoters, machos disliked the video, for once please accept and like!

Just do not try to find different meanings in this, the advertisement is pretty successful, just be sensible in your comments.

I was reading the comments; you talk about the brand's previous advertisements! They wanted to draw attention to an issue, although they can do regular staff for men who try to seem cute to women.

These comments are immediate replies to negative responses published under the video that principally scrutinize the brand's intention and serve to normalize hegemonic masculinity. This category points out that there is an ongoing tension between different comments. In this regard, hegemonic masculinity is dialogically negotiated, a process which points out the distinctive dynamics between separate discursive positions sustained by online commentators. As opposed to the positive responses, the comment section is dominated by negative responses to the advertisement by $62.4 \%$ ( $\mathrm{n}: 111)$. One of the sub-themes of this coding frame consists of comments that problematize the brand's intentions in engaging with cultural criticism (n: $38,34.2 \%$ ). Some of the comments highlight the following:

Although you know that sexual drives include violence, you propagate this the whole year, and then you act as if you take side with women...

Axe should facilitate this sensitivity to its other advertisements and should not use women as an instrument.

Not remaining silent? We know that two days later you will produce advertisements which commodify women.

You should say that we are sorry to use you as a sexual object., Capitalism :)

Does a brand who uses women as an object tell this? I would laugh at this.

Where were you before?

A brand which was using women as a sexual object five years ago is now taking side with women. 
The comments mainly blame the brand for instrumentalizing Women's Day and women's issues for commercial benefit. By referring to the brand's previous advertising image, which tended to objectify women's bodies, the company's new challenge to hegemonic masculinity is not considered a genuine attempt to engage in cultural criticism. Another common motive in this theme is the advertisement's narrative, since none of the comments that question the brand's intention refer to the advertisement's argument and dispute the possibility of an apology. Instead, these comments question the argument's sender by an interdiscursive analysis between the advertisement and the brand's previous gender narratives.

Axe's opposition to hegemonic masculinity is challenged by another group of comments that can be categorized as feminist criticism, which make up the $21.6 \%$ (n: 24 ) of the negative comments. The feminist critique of the advertisement is similar to the comments questioning the brand's sincerity, in the sense that both categories of negative reactions problematize the limits of the advertisement's emancipatory potential. Nevertheless, different from the first sub-theme, feminist criticism is more engaged with the content of the advertisement and explicates the limits of the gendered critique and transformation offered by the brand, rather than merely pointing out that the advertisement is a commercial project. In this respect, several of the comments narrate the following:

"Does not fit into the manhood" is itself a sexist sentence.

This is nonsense. Doing everything and then apologizing does not mean anything. We will not forgive with one apology as told in the video. Men who commit crimes should be sentenced, do not beat women the whole year and then beg for an apology for one day!

One and two apologies cannot bring deceased women back, you cannot arrive at anywhere by apologizing.

If you apologize, why only one day? We are afraid and exposed to violence the other days, and it is considered normal, why?!

I kill a man and apologize, how simple...

Apology is not enough, you cannot bring back the dead women by an apology.

I got your point but "does not fit into manhood?" This is sexist.

Nothing happens when you apologize, rape, murder, we see the news all around.

There are two main ways that online comments engage in a feminist negotiation of the advertisement's counter-narrative: by pointing out the sexism in the brand's slogan and by problematizing the apology. On the one hand, online comments highlight the essentializing of manhood as the "apologizing subject", which is manifested by the brand's slogan "Staying silent against what is done to women does not fit into manhood". In this regard, the critiques point out the brand's redefinition of manhood as a problematic attempt that legitimizes sexism, which sets up a paradox against the brand's intention to celebrate International Women's Day. On the other hand, comments pose a fundamentally crucial question concerning the violence 
and discrimination perpetrated by men against women: "is an apology even possible?" The online users' responses are oriented around this intriguing question, suggesting that an apology would only be a false facade for men's sympathy and calls for equality, as it would not transform the unequal gender relations and men's dominance.

The first sub-theme of responses questions the brand's intention by approving the brand's overall narrative, yet finding it inconsistent with the brand's commercial purposes. Different from this sub-theme, the feminist critique of the advertisement interrogates the potential of the brand's emancipatory argument through the discourse of apology, as apologizing is not seen as a valid performative utterance that would initiate a step towards defying hegemonic masculinity. The comments suggest that the advertisement tends to convert hegemonic masculinity into an apologetic masculinity, which offers an apology as a way of maintaining equal gender relations. However, the feminist critique does not consider this a viable and sustainable opportunity to facilitate gender equality.

The rejection of apologetic masculinity is further elaborated by users' comments that tend to reproduce hegemonic masculinity and sexism, which makes up the largest subcategory of negative responses against the advertisement $(44.2 \%, \mathrm{n}: 49)$. Under this subtheme, the majority of the comments oppose the idea of apologizing, and respond to this notion by insinuating that the advertisement aims to disempower men in various ways. Several of these comments remark the following about the discourse of apologizing as narrated by the advertisement:

I am not apologizing; did I do any of these? Every man is responsible for himself, why do you put all of them in the same box?

Why am I apologizing? To be born in this sex?

I am not apologizing. I did not do anything to apologize. You cannot generalize what five men did to every man. You put men in the place of a potential pervert.

I won't apologize for being born as a man.

A nonsense feminist advertisement that humiliates man, why would I apologize?

Do you apologize to that drag queen? Why?

The comments above reject the advertisement's call for an apology to deconstruct hegemonic masculinity. Although the genders of commentators are not revealed in their profiles, an important number of negative responses might have been published by male users as observed in their avatars and user names. The responses show that these users, who are supposedly male, resist relating themselves to the advertisement's social criticism of hegemonic masculinity and women's subjection. They tend to approach these subordinating acts within hegemonic masculinity as isolated, separate, and even "perverse" actions that are carried out by an insignificant number of men in the community. Rather than analyzing the broader cultural system of gender hierarchies, these commentators favour differentiating themselves from the "other men" who are perpetrators. In doing so, they reassert their identities as men who are prudish and have done nothing illegal to apologize for. 
Additionally, some comments accuse the advertisement of being "feminist" in a way that humiliates men by the very act of apology. These users feel that they are attacked by feminist criticism and that even their biological $\operatorname{sex}^{3}$ is humiliated. Although the advertisement points out cultural forms of discrimination rather than making biological remarks, male users put forward the biological argument as a defence mechanism in order to allege their identities. In this sense, their comments function as endeavours to restore, normalize, and legitimize hegemonic masculinity by downplaying its role in gender imbalance. Moreover, as the last comment states, they consider it irrelevant to apologize to a drag queen, which further reinforces the hegemonic masculine order through a homophobic discourse. In addition to the responses to apologetic masculinities as disempowering and threatening men, the comments also reject the advertisement's narrative as victimizing men:

One day they should also call a men's day, I am jealous.

I celebrate the women's day of all women, who do not generalize and humiliate men.

They produce the perception that all men in this country are perverts and insult men, humiliate men, and discriminate between men and women.

Just bury the men and close this issue, it has gone too long.

NO to positive discrimination towards women.

Come on, feminazis.

Recently, they are producing ads that humiliate and insult male sex.

How come feminazis received such an interest, in every discussion that I enter with feminists, I am labelled as a rapist; feminists are backward people.

The hostile comments against feminism, as evident in the use of the term "feminazi", continue in the above-given comments in which online users initiate an unabashedly antifeminist stance in deciphering the advertisement's oppositional narrative. The comments suggest that the advertisement propagates a feminist perspective, which generalizes a few rare incidents of women's subordination to all men in order to accuse, degrade, and ultimately dominate men. For them, the advertisement promotes apologetic masculinities to deprave men and advance women's dominance. The rejection of the advertisement's critical narrative and the overstatements regarding the humiliation of the male sex once again reveal efforts to recover the hegemonic masculine gender order by normalizing and legitimizing the power inequalities between genders.

Several users feel offended by the video's feminist criticism against manhood and since they take a defensive stance embracing their male identities, they could be considered male commentators. 


\section{Conclusion: Discursive Restoration of Hegemonic Masculine Order}

In his influential essay "Encoding/Decoding", cultural theorist Stuart Hall (1980) claims that all texts are polysemic, open to several interpretations by the readers/viewers who negotiate the encoded message according to their cultural contexts. The openness of the text paves the way for distinct and even conflicting interpretations of the text by audiences. Axe's two advertisements released for International Women's Day in Turkey point out the openness of the advertising text to which the audiences relate itself with different discursive strategies. The analysis of online comments shows that the celebrity figure, Can Bonomo, and his performance as a rock singer in the first advertisement makes a vast difference regarding how audiences decode the advertisement's main argument. Although the second advertisement similarly offers an apology and points out how men treat women unequally, it is not equally well received by the audiences compared to the Bonomo advertisement. This outcome points out the massive impact of celebrity culture on audiences, as they excitedly welcome the advertisement featuring this celebrity figure without directly engaging in analysis of the narrative. The audience's positive affirmation of Can Bonomo's presence shows that the Axe advertisement functions as "advertainment" (Kretchmer 2004), which poses a risk to the realization of an oppositional masculinity narrative. Despite the risk, the mode of advertainment proves a useful strategy for the brand to introduce its new critical masculinity language to its consumers. The comments about "We are not remaining silent" show that a critique of masculinity lacking an element of entertainment could easily detach consumers from feminist articulations. As Marshall McLuhan (1964) famously declared, "the medium is the message", the Axe experience shows that the format, composition, and the technical means by which the content is produced can significantly influence and alter how audiences correlate themselves to the advertising narrative.

Furthermore, the online responses to Axe's advertisements finally point out that the critical advertising discourse on hegemonic masculinity falls short of making a transformative impact on individuals. Despite advertainment as a narrative strategy, the advertisements fail to trigger the audiences' radical departure from hegemonic masculinity as the users tend to recapture hegemonic masculine discourses even through their seemingly critical stances. In this regard, the reproduction of hegemonic masculinity through online comments points to the challenging and inadequate potential of deconstructing discourses regarding hegemonic masculinity in the performative gender order. The online comments proceed in such a way as to thwart the perceived threat posed by the advertisements against hegemonic masculine discursivity. By considering gender as a performative domain exercised in language, it can be argued that online comments set up a significant ground for strife between competing discourses on hegemonic masculinity, which tends to reconstruct the existing gender hierarchies. The ways in which the advertisements are discursively neutralized and restored comprehensively demonstrate the cultural limits and obstacles in promoting critical narratives towards hegemonic masculinity in the post-feminist era. 


\section{Acknowledgments}

I would like to thank the two anonymous reviewers of this article for their insightful comments and suggestions.

\section{References}

Atuk, Tankut. 2019. "Comrades-in-[Each Other's]-Arms: Homosociality, Masculinity and Effeminacy in the Turkish Army." Men and Masculinities August 2019.

Barber Kristen and Tristan Bridges. 2017. "Marketing Manhood in a 'Post-Feminist' Age." Contexts 16(2): 38-43.

Beasley, Christine. 2008. "Rethinking Hegemonic Masculinity in a Globalizing World." Men and Masculinities 11(1): 86-103.

Boratav, Hale Bolak, Guler Okman Fisek, and Hande Eslen Ziya. 2014. "Unpacking Masculinities in the Context of Social Change: Internal Complexities of the Identities of Married Men in Turkey." Men and Masculinities 17(3): 299-324.

Buschmeyer, Anna and Diana Lengersdorf. 2016. "The Differentiation of Masculinity as a Challenge for the Concept of Hegemonic Masculinity.” NORMA (11)3: 190-207.

Connell, Raewyn W. and James W. Messerschmidt. 2005. "Hegemonic Masculinity: Rethinking the Concept." Gender and Society 19(6): 829-859.

Connell, Raewyn. 1987. Gender and Power. Sydney: Allen and Unwin.

Connell, Raewyn. 1995. Masculinities. Cambridge: Polity Press.

Ekşi, Betül. 2019. "Police and Masculinities in Transition in Turkey: From Macho to Reformed to Militarized Policing." Men and Masculinities 22(3): 491-515.

Feasey, Rebecca. 2009. "Spray More, Get More: Masculinity, Television Advertising and the Lynx Effect." Journal of Gender Studies 18(4): 357-368.

Gee, Sarah and Steve J. Jackson. 2012. "Leisure Corporations, Beer Brand Culture, and the Crisis of Masculinity: The Speight's 'Southern Man' Advertising Campaign.” Leisure Studies 31(1): 83-102.

Gill, Rosalind. 2007. "Postfeminist Media Culture: Elements of a Sensibility." European Journal of Cultural Studies 10(2): 147-166.

Gill, Rosalind. 2008. "Empowerment/Sexism: Figuring Female Sexual Agency in Contemporary Advertising." Feminism \& Psychology 18(2): 35-60.

Goffman, Erving. 1979. Gender Advertisements. New York: Harper Torchbooks.

Goldman, Robert. 1992. Reading Ads Socially. London and New York: Routledge.

Greenebaum, Jessica and Brandon Dexter. 2018. "Vegan Men and Hybrid Masculinity." Journal of Gender Studies 27(6): 637-648.

Hall, Stuart. 1980. “Encoding/Decoding." Pp. 117-127 in Culture, Media, Language-Working Papers in Cultural Studies 1972-79, edited by Stuart Hall, Doothy Hobson, Andrew Lowe, and Paul Willis. London: Routledge.

Hardin, Marie, Kathleen M. Kuehn, Hillary Jones, Jason Genovese, and Murali Balaji. 2009. “"Have You Got Game?' Hegemonic Masculinity and Neo-Homophobia in U.S. Newspaper Sports Columns.” Communication, Culture and Critique 2(2): 182-200.

Harrison, Claire. 2008. "Real Men Do Wear Mascara: Advertising Discourse and Masculine Identity." Critical Discourse Studies 5(1): 55-74. 
Jackson, Peter. 1994. "Black Male: Advertising and the Cultural Politics of Masculinity." Gender, Place \& Culture 1(1): 49-59.

Jester, Natalie. 2019. "Army Recruitment Video Advertisements in the US and UK since 2002: Challenging Ideals of Hegemonic Military Masculinity?" Media, War \& Conflict 14(1): 57-74.

Jhally, Sut. 1990. The Codes of Advertising: Fetishism and the Political Economy of Meaning in Consumer Society. New York, London: Routledge.

Jhally, Sut. 2006. “Advertising, Gender and Sex: What's Wrong with a Little Objectification?”Pp. 163-176 in The Spectacle of Accumulation: Essays in Culture, Media, \& Politics, edited by Sut Jhally. New York: Peter Lang.

Johansson, Thomas and Andreas Ottemo. 2015. "Ruptures in Hegemonic Masculinity: The Dialectic between Ideology and Utopia." Journal of Gender Studies 24(2): 192-206.

Keskin, Fatih. 2018. "Masculinity in Gender Relations: Hegemonic Masculinity and Masculine Power Discourse in Turkey." Public Integrity 20(1): 93-106.

King, Claire Sisco. 2009. "It Cuts Both Ways: Fight Club, Masculinity, and Abject Hegemony." Communication and Critical/Cultural Studies 6(4): 366-385.

Klasson, Marcus and Sofia Ulver. 2015. "Masculinising Domesticity: An Investigation of Men's Domestic Foodwork.” Journal of Marketing Management 31(15-16): 1652-1675.

Kretchmer, Susan B. 2004. “Advertainment.” Journal of Promotion Management 10(1-2): 37-54.

Lazar, M. Michelle. 2014. "Recuperating Feminism, Reclaiming Femininity: Hybrid Postfeminist I-Dentity in Consumer Advertisements." Gender and Language 8(2): 205-224.

Leader, Caroline F. 2019. "Dadvertising: Representations of Fatherhood in Procter \& Gamble's Tide Commercials." Communication, Culture and Critique 12(1): 72-89.

Leiss, William, Stephen Kline, and Sut Jhally. 1990. Social Communication in Advertising: Persons, Products \& Images of Well-Being. Ontario: Nelson Canada.

Lune, Howard and Bruce L. Berg. 2017. Qualitative Research Methods for the Social Sciences. Ninth Edition. Harlow: Pearson.

Luyt, Russell. 2012. "Representation of Masculinities and Race in South African Television Advertising: A Content Analysis.” Journal of Gender Studies 21(1): 35-60.

McCluskey Megan. 2019. "Gillette Makes Waves With Controversial New Ad Highlighting 'Toxic Masculinity'.” Time. Retrieved March 20, 2020 (https://time.com/5503156/gillette-razors-toxicmasculinity/).

McLuhan, Marshall. 1964. Understanding Media: The Extensions of Man. New York: McGraw-Hill.

McRobbie, Angela. 2004. "Post-feminism and Popular Culture." Feminist Media Studies 4(3): 255-264.

Messerschmidt, James W. 2019. "The Salience of 'Hegemonic Masculinity'." Men and Masculinities 22(1): 85-91.

Murray, Dara Persis. 2013. "Branding 'Real' Social Change in Dove's Campaign For Real Beauty." Feminist Media Studies 13(1): 83-101.

Nas, Alparslan. 2017. "Erkekler de Ağlar, Ama... Axe Reklamındaki Hegemonik Erkeklik Eleştirisinin Yorumlanma Biçimleri [Men Cry Too, But... Interpretation of the Critique of Hegemonic Masculinity in Axe Advertisement].” Erciyes Illetişim Dergisi 5(2): 62-80.

Nudd, Tim. 2017. “Axe Tackles 'Toxic Masculinity' by Revealing How Deeply Young Men Struggle With It." Adweek. Retrieved March 20, 2020 (https://www.adweek.com/brand-marketing/axetackles-toxic-masculinity-by-revealing-how-deeply-young-men-struggle-with-it/).

Ozbay, Cenk and Ozan Soybakis. 2020. "Political Masculinities: Gender, Power, and Change in Turkey Social Politics." International Studies in Gender, State \& Society 27(1): 27-50.

Patterson, Maurice and Richard Elliott. 2002. "Negotiating Masculinities: Advertising and the Inversion of the Male Gaze." Consumption, Markets and Culture 5(3): 231-249. 
Prody, Jessica M. 2015. "Protesting War and Hegemonic Masculinity in Music Videos: Audioslave's 'Doesn't Remind Me'.” Women's Studies in Communication 38(4): 440-461.

Rogers, Richard A. 2008. "Beasts, Burgers, and Hummers: Meat and the Crisis of Masculinity in Contemporary Television Advertisements." Environmental Communication 2(3): 281-301.

Scheibling, Casey and Marc Lafrance. 2019. "Man Up but Stay Smooth: Hybrid Masculinities in Advertising for Men's Grooming Products.” The Journal of Men's Studies 27(2): 222-239.

Schroeder, Jonathan E. and Detlev Zwick. 2004. "Mirrors of Masculinity: Representation and Identity in Advertising Images." Consumption Markets \& Culture 7(1): 21-52.

Towns, Alison J., Christy Parker, and Phillip Chase. 2012. "Constructions of Masculinity in Alcohol Advertising: Implications for the Prevention of Domestic Violence." Addiction Research \& Theory 20(5): 389-401.

Williamson, Judith. 1978. Decoding Advertisements: Ideology and Meaning in Advertising. London: Marion Boyars.

Williams, Raymond. 2000. "Advertising: the Magic System.” Advertising \& Society Review 1(1), doi:10.1353/asr.2000.0016.

\section{Author}

Alparslan Nas is an Associate Professor at Marmara University Faculty of Communication in Istanbul, Turkey. His research critically analyzes the representations of power, ideologies and resistances in Turkish media and visual culture. He is the author of Media Representations of the Cultural Other in Turkey, published by Palgrave Macmillan in 2018.

Contact: alparslan.nas@marmara.edu.tr 